\title{
Atmospheric air density analysis with Meteo- 40S wind monitoring system
}

\author{
Dănuț Zahariea ${ }^{1, *}$, and Dorin Emil Husaru ${ }^{2}$ \\ 1"Gheorghe Asachi" Technical University of Iași, Department of Fluid Mechanics, Fluid Machinery \\ and Fluid Power Systems, D. Mangeron 59A, Iași, România \\ 2"Gheorghe Asachi" Technical University of Iași, Department of Mechanical Engineering, \\ Mecatronics and Robotics, D. Mangeron 43, Iași, România
}

\begin{abstract}
In order to estimate the wind potential of wind turbine sites, the wind resource maps can be used for mean annual wind speed, wind speed frequency distribution and mean annual wind power density determination. The general evaluation of the wind resource and the wind turbine ratings are based on the standard air density measured at sea level and at $15^{\circ} \mathrm{C}$, $\rho_{s}=1.225 \mathrm{~kg} / \mathrm{m}^{3}$. Based on the experimental data obtained for a continental climate specific location, this study will present the relative error between the standard air density and the density of the dry and the moist air. Considering a cold day, for example on Friday $10^{\text {th }}$ February 2017, on 1second measurement rate and 10-minute measuring interval starting at $16: 20$, the mean relative errors obtained are $10.4145 \%$ for dry air, and $10.3634 \%$ for moist air. Based on these results, a correction for temperature, atmospheric air pressure and relative humidity should be always considered for wind resource assessment, as well as for the predicting the wind turbines performance.
\end{abstract}

\section{Introduction}

Wind turbine energy generation involve complex aspects such as: wind energy conversion [1], planning and building permits (regional framework, building permit, assessment studies of environmental impact, connecting turbines to the electrical grid), transportation problems, erection on the site, grid connection, operating and monitoring, safety aspects, maintenance and repair [2,3], as well as economics of wind energy, [4]. All these aspects are covered by technical, environmental and economic studies, standards, regulations, researches all over the world, and represent after all, work done by human resources.

However, the most important aspect, which represent the starting point of the wind turbine energy generation process is the wind resource assessment, [5], which allows to obtain important data about the wind potential, like mean annual wind speed, wind speed frequency distribution and mean annual wind power density. The wind power density, $P\left[\mathrm{~W} / \mathrm{m}^{2}\right]$, which represent the power in the upstream wind, is defined by the relationship, [6]:

$$
P=1 / 2 \cdot \rho V^{3}
$$

where $\rho\left[\mathrm{kg} / \mathrm{m}^{3}\right]$ is the air density, and $V[\mathrm{~m} / \mathrm{s}]$ is the mean annual wind speed.

${ }^{*}$ Corresponding author and co-author(s): dzahariea@yahoo.com 
Analyzing the equation (1), it can be observed that the wind speed has an exponent of 3 , so even small change in wind speed leads to major changes in wind power density. It is noted also, the presence of the air density, and even if its exponent is 1, it plays an important role in the evaluation of the wind power density, which will be further discussed in this paper.

The general evaluation of the wind resource on the large scale should be performed using the wind resource data stored in the so-called wind atlases. Based on the meteorological data gathered mainly from all national weather stations, and using numerical wind models, national wind resource estimates have been obtained in different forms: tables, charts and maps. Collecting wind data from many countries allows obtaining the regional wind resource data, such as the European Wind Atlas [7], or the Global Wind Atlas, [8]. All these online wind resource data are available, generally, at three heights 50,100 and $200 \mathrm{~m}$. Further, wind speed can be extrapolated to the wind turbine rotor height, using different models of the wind speed distribution with altitude in the atmospheric boundary layer, like the logarithmic and power laws, [2]. After the general evaluation of the wind resource has been successfully completed and a potentially suitable wind turbine site has been selected, a more deeply analysis should be performed, this time on a small scale in order to obtain more precise information on the site-specific wind resource. The first approach is the analysis of the site topography looking after microscale effects such as ridges oriented perpendicular to the prevailing wind direction, highest elevations, and areas where local winds can funnel, [5]. However, the most important analysis is the on-site wind monitoring for at least one year, using specialized wind measurement systems.

It is very important to observe that the general evaluation of the wind resource is based on the standard air density measured at sea level and at $15^{\circ} \mathrm{C}, \rho_{s}=1.225 \mathrm{~kg} / \mathrm{m}^{3}$, [6]. However, there are regions around the world where the air density has very different values from the standard air density, due to high fluctuations of temperatures, humidity and atmospheric air pressure. For example, in [9] has been found that the monthly air density is at most $6 \%$ less than the standard air density for the tropical climates of Trinidad and Tobago. Measuring the temperature, atmospheric air pressure and relative humidity in Gyor, Hungary from 2004 to 2006 , it has been found that, even if the average air density $\left(1.229 \mathrm{~kg} / \mathrm{m}^{3}\right)$ is rather close to the standard air density, the estimation of the wind power production was $16 \%$ more accurate, [10]. Another parameter that modifies the air density is the site elevation; the impact of the air density variation with altitude (up to $3000 \mathrm{~m}$ ) on functional performances of a threebladed small wind turbine has been investigated in [11], and it has been established that the performance of a wind turbine designed to work at sea level decrease with increasing altitude.

In this study, the influence of the measured values of temperature, atmospheric air pressure and relative humidity on the air density will be comparatively analyzed, with respect to the standard air density by computing the relative errors between the standard air density and the density of the dry, respectively the moist air, for a continental climate specific location with latitude 47,155876 and longitude 27,60095. The experimental data will be obtained with the Meteo-40S wind monitoring system which is composed by Ammonit Meteo-40S data logger [12], Vaisala barometric pressure sensor [13], Galltec hygro/thermo sensor [14], and Thies ultrasonic 2D anemometers, [15].

\section{Wind monitoring system description}

The wind monitoring system about we will discuss in this paper, is located in the Wind Turbine Field Test Laboratory from the Department of Fluid Mechanics, Fluid Machinery and Fluid Power Systems, Faculty of Machine Manufacturing and Industrial Management at "Gheorghe Asachi" Technical University of Iași, Romania. The coordinates of the wind monitoring system are: latitude 47,155876 and longitude 27,60095. Using the Google Earth application, the wind monitoring system location can be observed in Fig. 1. 
The wind monitoring system is identified with the name MFMAHP Data Logger selected by the user and the data logger code D153031 provided by the producer.

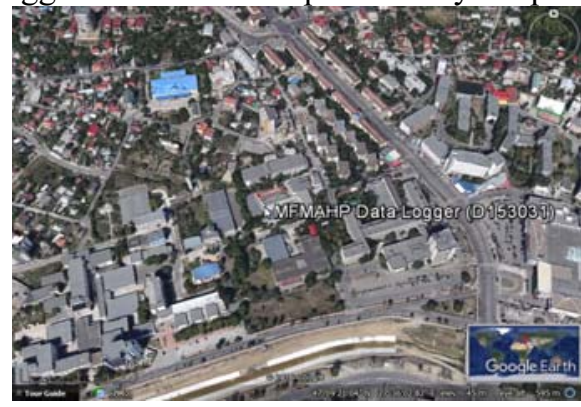

Fig. 1. Location of the wind monitoring system.

There are 4 sensors connected with the Meteo-40S data logger: 1 barometric, 1 hygro/thermo sensor, and 2 anemometers:

- The atmospheric air pressure is measured with the PTB110.2 barometric sensor produced by Vaisala, [13]. The principal technical characteristics of the barometric sensor are: pressure range $600 \div 1100 \mathrm{hPa}$, total accuracy $\pm 0.3 \mathrm{hPa}$ for $+15 \div+25^{\circ} \mathrm{C}$, and $\pm 1.5 \mathrm{hPa}$ for $-40 \div+60^{\circ} \mathrm{C}$.

- The air temperature and relative humidity are measured with a Galltec hygro/thermo sensor, [14]. The hygro/thermo sensor is placed inside a weather and radiation shield. The principal technical characteristics of the hygro/thermo sensor are: temperature range $-30 \div+70{ }^{\circ} \mathrm{C}$, temperature accuracy $\pm 0.2 \mathrm{~K}$, relative humidity range $0 \div 100 \%$, relative humidity range $\pm 2 \%$.

- The 2D ultrasonic anemometers are produced by Thies, [15], and can measure two velocity components ( $u$ and $v$ ), as well as the wind direction. The principal technical characteristics of ultrasonic anemometers are: wind speed range $0 \div 75 \mathrm{~m} / \mathrm{s}$, accuracy $\pm 0.1 \mathrm{~m} / \mathrm{s} \leq 5 \mathrm{~m} / \mathrm{s}, \pm 2 \%$ of meas. value $>5 \mathrm{~m} / \mathrm{s}$, resolution $0.1 \mathrm{~m} / \mathrm{s}$; wind direction range $0 \div 360^{\circ}$, accuracy $\pm 1^{\circ}$, resolution $1^{\circ}$.

The data logger, the barometric sensor, the power supply and the electrical connectors are placed inside a steel cabinet. The sensors configuration is performed using the data logger, for example in remote control system, through a Web browser application. After the physical connection, the data logger is able to detect the type of sensors. There are two important parameters that user should carefully select: the measurement rate (selected 1-second) and the file statistics interval (selected 10-minutes).

\section{Experiment}

The experimental data are stored in the data logger internal memory at the sample rate of 1 second for all sensors, averaged on a 10-minute basis and saved in a data file on a daily basis. The daily data file, which is saved in a CSV file format, can be downloaded locally using a USB connection, or remotely using an Ethernet connection and the same Web browser application. Moreover, the data source, stored in the data-logger internal memory at the measurement rate, can be analyzed by downloading on different intervals: 10-minute, 1-hour, 1-day, and 1-week. The Meteo-40S wind measurement system uses digital signature and encryption methods in order to protect the experimental data integrity and authenticity.

For this paper, the experimental data measured on Friday, $10^{\text {th }}$ February 2017, on a 10minutes interval starting at 16:20 will be analyzed. The experimental data are presented in Fig. 2, a) (for the temperature, $t\left[{ }^{\circ} \mathrm{C}\right]$ ), Fig. 2, b) (for the atmospheric air pressure, $p_{a}[\mathrm{hPa}]$ ), and Fig. 2, c) (for the relative humidity, $\varphi[\%]$ ). 


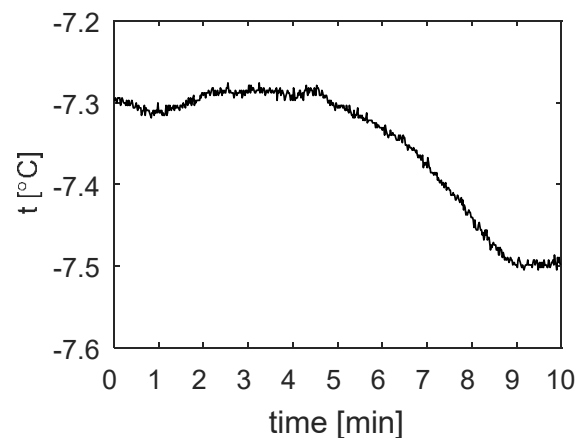

a) temperature

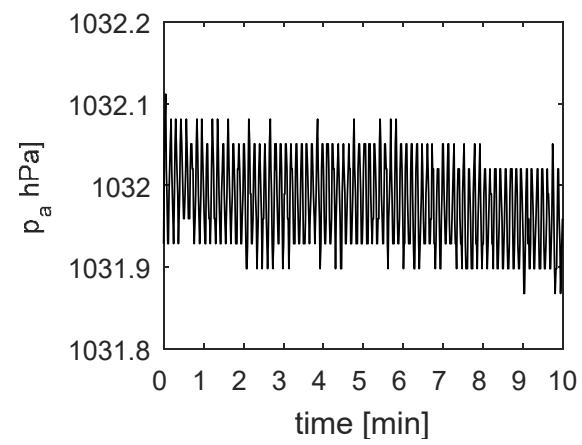

b) atmospheric air pressure

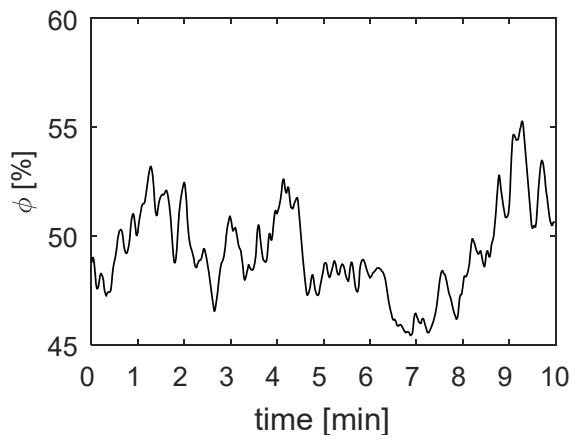

c) relative humidity

Fig. 2. Experimental data.

\section{Discussion}

Based on the experimental data presented in Fig. 2, the air density has been computed and presented comparatively for dry air $\left(\rho_{d}\right)$, and moist air $\left(\rho_{m}\right)$, in Fig. 3.

For the dry air, the ideal gas law has been used:

$$
\rho_{d}=\frac{p_{a}}{R T}
$$

where $R[\mathrm{~J} / \mathrm{kg} \cdot \mathrm{K}]$ is the specific gas constant for dry air, and $T[\mathrm{~K}]$ is the absolute temperature.

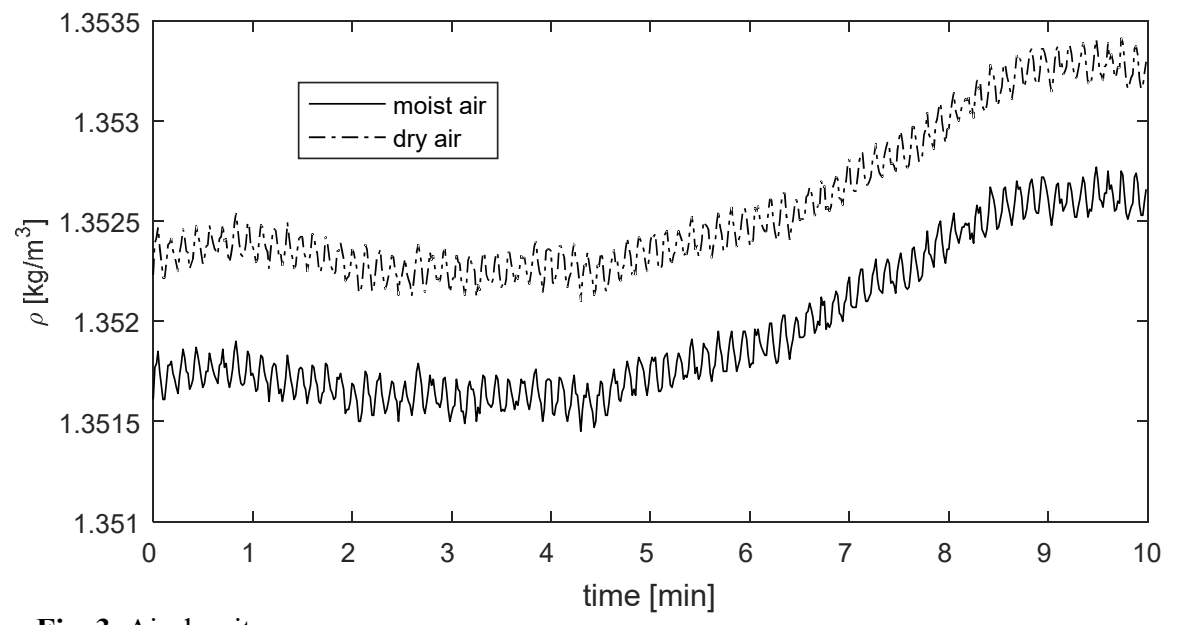

Fig. 3. Air density. 
For the moist air the following relationship has been used, [12]:

$$
\rho_{m}=\frac{1}{T}\left[\frac{p_{a}}{R}-\varphi \cdot p_{v}\left(\frac{1}{R}-\frac{1}{R_{v}}\right)\right]
$$

where $p_{v}$ and $R_{v}$ are the water vapor pressure and the gas constant of water vapor.

Considering the standard air density value $\rho_{s}=1.225 \mathrm{~kg} / \mathrm{m}^{3}$ as the reference value, the relative errors for dry air density $\varepsilon_{s d}[\%]$, and for moist air density $\varepsilon_{s m}[\%]$ will be computed with the equations (4) and (5). Similarly, one can calculate the relative error between the dry air density and the moist air density, $\varepsilon_{m d}(6)$.

$$
\begin{aligned}
\varepsilon_{s d} & =\frac{\left|\rho_{s}-\rho_{d}\right|}{\rho_{s}} 100[\%] \\
\varepsilon_{s m} & =\frac{\left|\rho_{s}-\rho_{m}\right|}{\rho_{s}} 100[\%] \\
\varepsilon_{m d} & =\frac{\left|\rho_{m}-\rho_{d}\right|}{\rho_{m}} 100[\%]
\end{aligned}
$$

The relative errors are presented in Fig. 4, a) for the dry air density, in Fig. 4. b) for the moist air density, and in Fig. 4. c) for the relative error between the dry air density and the moist air density. The mean values of the relative errors are: $10.4145 \%$ for dry air, $10.3634 \%$ for moist air, and $0.0462 \%$ for the relative error between the dry and the moist air density.

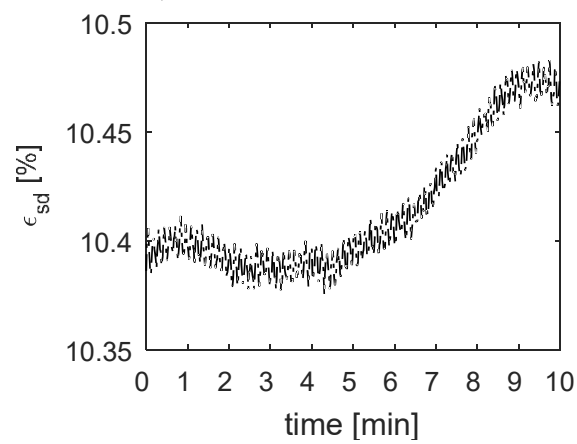

a) dry air, mean value $10.4145 \%$

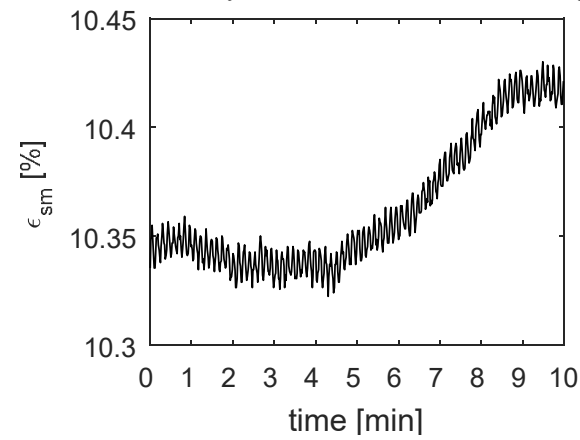

b) moist air, mean value $10.3634 \%$

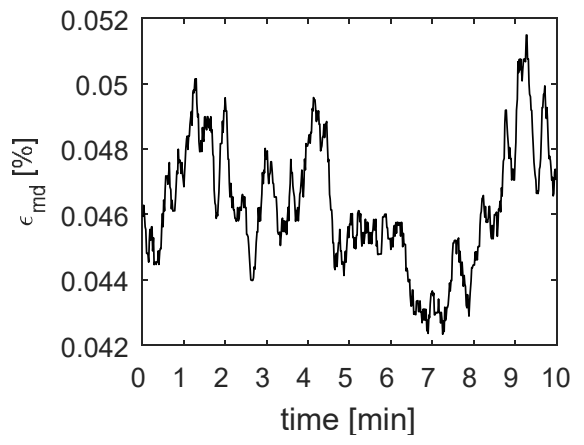

c) dry air with respect with moist air, mean value $0.0462 \%$

Fig. 4. Relative error

\section{Conclusions}

Measuring the temperature, the atmospheric air pressure and the relative humidity on 1second measurement rate and 10-minute measuring interval, starting at 16:20 on Friday $10^{\text {th }}$ February 2017, for the continental climate location defined by latitude 47,155876 and longitude 27,60095 (in Iași, Romania), computing the density for the dry and the moist air, 
and the corresponding relative errors with respect to the standard air density, it has been found that these errors are $10.4145 \%$ for dry air, and $10.3634 \%$ for moist air. In addition, the relative error between the dry and the moist air density is $0.0462 \%$. Based on these results, a correction, at least for temperature and atmospheric air pressure, should be always considered for wind resource assessment, as well as for predicting the wind turbines performance. For better accuracy, the relative humidity should also be considered, thus, the moist air density should be used, instead of standard air density. The high measurement quality of sensors combined with a high-performance data logger, recommended the Meteo-40S wind measurement system as one of the most advanced product for wind resource assessment and wind farm monitoring, as well as for basic meteorological data recording and processing.

The authors would like to acknowledge the technical resources offered by the Laboratory of Wind Energy 1 - Wind Turbine Field Test, from the Department of Fluid Mechanics, Fluid Machinery and Fluid Power Systems, "Gheorghe Asachi” Technical University of Iași, Romania. The Laboratory of Wind Energy 1 - Wind Turbine Field Test has been equipped with technical resources with the financial support of the grant ENERED, POSCCE-A2-O2.2.1-2009-4, ID 911.

\section{References}

1. M. Cheng, Y. Zhu, Energ. Convers. Manage., 88, (2014)

2. E. Hau, Wind Turbines. Fundamentals, Technologies, Application, Economics (Springer, Berlin, 2006)

3. K. Dai, A. Bergot, C. Liang, W.-N. Xiang, Z. Huang, Renew. Energ. 75 (2015)

4. S. Krohn, P.-E. Morthorst, S. Awerbuch, The Economics of Wind Energy. A report by the European Wind Energy Association, http://www.ewea.org/fileadmin/ewea documents/documents/publications/reports/Economics_of_Wind_Main_Report_FINA L-lr.pdf, accessed 9.02.2017

5. B.H. Bailey, S.L. McDonald, D.W. Bernadett, M.J. Markus, Wind Resource Assessment Handbook, http://www.nrel.gov/docs/legosti/fy97/22223.pdf, accessed 9.02.2017

6. J.P. Hennessey, J. Appl. Meteorol. 162 (1977)

7. I. Troen, L.E. Petersen, European Wind Atlas, (Riso National Laboratory, Roskilde, Denmark, 1989)

8. Technical University of Denmark, Department of Wind Energy, Global Wind Atlas, http://globalwindatlas.com/map.html, accessed 9.02.2017

9. X.T. Chadee, R.M. Clarke, ISRN Renew. Energ., ID 378027 (2013).

10. Z. Farkas, Considering Air Density in Wind Power Production, Cornell University Library, arXiv:1103.2198, https://arxiv.org/pdf/1103.2198.pdf, accessed 31.03.2017

11. A. Pourrajabian, M. Mirzaei, R. Ebrahimi, D. Wood, J. Wind Eng. Ind. Aerod. 126 (2014)

12. Ammonit Measurement $\mathrm{GmbH}$, Wind Measurement for Site Assessment, http://www. ammonit.com/en/wind-solar-messsysteme/windmessung, accessed 01.02.2017.

13. Vaisala GmbH, PTB110 Barometer for Industrial Use, http://www.vaisala.com/Vaisala \%20Documents/Brochures\%20and\%20Datasheets/PTB110-Datasheet-B210681EN-CLoRes.pdf , accessed 9.02.2017

14. Galltec Mess- und Regeltechnik GmbH, Humidity and Temperature Sensors, https:// www.galltec-mela.de/product/humidity-and-temperature-sensors-for-hvac-1series/114/EN, accessed 01.02.2017

15. Thies Clima GmbH, Wind Ultrasonic Anemometer, https://www.thiesclima. com/en/Products/ Wind-Ultrasonic-Anemometer/, accessed 01.02.2017 